\title{
A GLOCALIZAÇÃO DA EDUCAÇÃO NA REGIÃO DO ARAGUAIA - PELA JANELA DE CASALDÁLIGA
}

\author{
THE GLOCALISATION OF EDUCATION IN THE REGION OF ARAGUAIA - BY THE \\ CASALDÁLIGA WINDOW
}

Ilma Ferreira Machado. Doutora em Educação pela Universidade Estadual de Campinas (UNICAMP). Professorado Departamento de Pedagogia e do PPGEdu (UNEMAT).

E-mail:.ilma.ferreiramachado@gmail.com

Ana Maria Di Renzo

Doutora em Linguística pela Universidade Estadual de Campinas (UNICAMP). Professora do PPGL/UNEMAT e, atualmente, também é reitora (UNEMAT).

E-mail: arenzo@unemat.br

Maria de Lourdes Jorge de Sousa Mestra em Educação pela Universidade do Estado de Mato Grosso (UNEMAT). Professora da rede pública de Educação Básica de Mato Grosso (SEDUC/MT).

E-mail: loujorgelb@gmail.com

Edineth Sousa França Silva Alves

Mestra em Linguística pela Universidade do Estado de Mato Grosso (UNEMAT). Professora da rede pública de Educação Básica de Mato Grosso (SEDUC/MT). Doutorando na Universidade do Estado de Mato Grosso (UNEMAT). E-mail: edinethfran@hotmail.com

Resumo: O presente artigo aborda aspectos da educação na região do Araguaia, nas décadas de 80 e 90 do século XX, referenciadas em documentos e nas dissertações de mestrado e artigos das autoras. O intuito é tecer uma compreensão e levar a refletir como, discursivamente, Casaldáliga (2004) define uma perspectiva libertadora para a educação que foi institucionalizada por meio da Prelazia de São Félix do Araguaia-MT nesse período. Para tanto buscou-se conhecer os princípios da "educação libertadora", proposta pelo educador Paulo Freire e pelo Filósofo Theodor Adorno e articulá-los à noção de "glocalização" apresentada por Casaldáliga (op. cit). As reflexões partem de um diálogo com a Teoria Crítica e a perspectiva crítico-dialética, bem como a apropriação de contribuições teórico-metodológicas da Análise de Discurso franco-brasileira, desenvolvida por Michel Pêcheux na França e por Eni Orlandi no Brasil, com o intuito de compreender os efeitos de sentido de mundialidade, globalização e intersetorialidade nos modos de produção da educação no Araguaia.

Palavras-chaves:Discurso.Educação. Emancipação. Glocalização. Libertação.

Abstract: This article deals with aspects of education in the Araguaia region, in the 1980s and
1990s, referenced in documents and dissertation sand article soft he authors. The intention is to
weave an understanding and lead to reflect how, discursively, Casaldáliga (2004) defines a
liberating perspective for education that was institutionalized through the Prelature of São Félix
do Araguaia-MT in this period. In order to do so, we so ought to know the principles of 
"liberating education" proposed by educator Paulo Freire and the philosopher Theodor Adorno and articulate them with the notion of "glocalization" presented by Casaldáliga (op. cit.). The reflections start from a dialogue with the Critical Theory and the critical-dialectical perspective, as well as the appropriation of the critical-methodological contributions of the Franco-Brazilian Discourse Analysis, developed by Michel Pêcheux in France and by Eni Orlandi in Brazil, with the aim to understand the effects of sense of globalization, globalization and intersectoriality in the modes of production of education in Araguaia.

Keywords: Speech. Education. Emancipation. Glocalization. Release.

\section{Introdução}

A região conhecida como região do Araguaia, localizada á nordeste de Mato Grosso tornou-se conhecida nacionalmente, a partir do final da década de 1970, devido à atuação do bispo catalão D. Pedro Casaldáliga, em defesa dos indígenas, peões e posseiros que ali viviam. O religioso atuou de forma contundente, até a sua aposentadoria, em defesa dos pobres marginalizados, especialmente, dos moradores da região identificada. Suas ideias eram materializadas em projetos alternativos de formação política, saúde, educação e ao anunciar o evangelho. Na década de 1990 com o avanço do fenômeno da globalização, Casaldáliga defendia veementemente a educação libertadora como instrumento de emancipação dos pobres, e ao problematizar a educação na região do Araguaia, se utilizava com frequiência do termo "Glocalização" da educação. O texto que ora se apresenta referencia-se numa abordagem qualitativa de pesquisa, tendo como procedimento a análise de documentos. $\mathrm{O}$ texto foca questões da educação na região do Araguaia, buscando compreender os fundamentos e princípios da educação propagada por D. Pedro Casaldáliga, observando, possíveis relações com as teorias de educação libertadora de Paulo Freire e de educação para a emancipação de Theodor Adorno. Este estudo ganha relevância por procurar evidenciar a concepção e os conceitos de educação que orientava as práticas políticas e os discursos no campo espiritual de uma das maiores lideranças religiosas do país, que é o Bispo emérito da Prelazia de São Félix do Araguaia, Pedro Casaldáliga. Dessa forma, registra, também, as contribuições de D. Pedro para a construção da educação no Araguaia.

\section{Educação e Emancipação da Classe Trabalhadora}


Inscrevemos nosso trabalho de leitura da educação no Araguaia na Teoria Crítica, haja vista que temos o entendimento de que o direito à educação é apenas um dos direitos negados à classe trabalhadora e que, para superar as desigualdades sociais, é preciso a construção de outra ética, outros valores, outras relações políticas, sociais, econômicas e culturais, pressupõe outro projeto de sociedade. E estabelecemos um diálogo entre a perspectiva críticoemancipatória da educação e uma teoria do discurso, tal como a $\mathrm{AD}$, tendo em vista que seu caráter epistemológico interdisciplinar nos permite compreender que língua e história entrecruzam-se e possibilitam sentidos, os quais constituem-se na relação intrínseca e necessária entre o linguístico e o ideológico.

Pensar outra sociedade é possível, mas nos parece exigir a construção de uma consciência coletiva, principalmente, dos trabalhadores, que são expropriados de seus direitos básicos. A partir dessa premissa tem se buscado na educação contribuições importantes para o enfrentamento dessa situação.

Atribuir à educação a responsabilidade de alavancar transformações na sociedade capitalista, rumo a uma sociedade pautada na justiça social e na solidariedade, exige a definição de um projeto alternativo de educação muito bem delineado, integrado a um projeto de sociedade, capaz de se contrapor e provocar mudanças no modelo competitivo e excludente da atualidade. Faz-se necessário, ainda, definir o papel da educação no processo de transformação da sociedade. Seria pensar um projeto de educação na perspectiva da educação que, "se pauta no diálogo da Pedagogia Crítica, com objetivos políticos de emancipação, de luta por justiça e igualdade social". (CALDART, 2004, p. 18).

A educação emancipatória da classe trabalhadora, postulada pelos movimentos sociais e setores progressistas da sociedade, vem sendo discutida por diversos autores ao longo do percurso histórico das lutas de classes e da história da educação. Para dialogar sobre a educação emancipatória/transformadora trazemos algumas contribuições do filósofo alemão Theodor Adorno, do educador brasileiro Paulo Freire, ambos do século XX e buscamos uma articulação entre o pensamento desses autores e as ações de Dom Pedro Casaldáliga, bispo emérito da Prelazia de São Félix do Araguaia-MT, em torno do desenvolvimento da educação no Araguaia, nas décadas finais do século XX e o modo como ele a significa, já no século XXI como uma educação que se constitui na perspectiva da glocalização. 
O processo histórico da humanidade mostra que todas as vezes que uma nação está diante de um grande problema, uma crise de qualquer ordem, busca-se na educação uma resposta, dando a ela um poder que nem sempre é conferido na prática.

Podemos conferir essa força motriz creditada à educação no pensamento do filósofo Theodor Adorno - quando, em um de seus debates com Becker, realizado na rádio de Hessen, em1969, defendeu veementemente a educação para a emancipação como única forma de evitar a repetição da barbárie que levou a Auschwitz na Alemanha, na época de Hitler. "A exigência que Auschwitz não se repita é a primeira de todas para a educação [...] Qualquer debate acerca de metas educacionais carece de significado e importância frente a essa meta: que Auschwitz não se repita" (ADORNO, 1995, p. 119).

Representante da Teoria Crítica, Adorno preocupou-se com esta discussão, traçando reflexões acerca das possibilidades e entraves dos processos formativos na sociedade capitalista, denunciando a semiformação e a racionalidade instrumental que levam à barbárie e alertando para a necessidade de uma educação que possibilite uma racionalidade emancipatória.

Adorno (1995), ao falar de educação e emancipação, referencia-se à Alemanha do Século XX. Ele discutia a necessidade da emancipação humana, mas, admitia a dificuldade de fazê-la no contexto da Alemanha daquela época, devido às contradições sociais. Ao reconhecer as dificuldades para a concretização da emancipação, afirmava que a única maneira de promover a emancipação humana e evitar a barbárie, "é simplesmente começar despertando a consciência quanto ao que os homens são enganados de modo permanente, pois hoje em dia o mecanismo da ausência de emancipação é o mundus vult decipi em âmbito planetário, de que o mundo quer ser enganado" (ADORNO, 1995, p. 183).

Nesse ponto, o que Adorno defende é encontrado em outros contextos também. No Brasil, Paulo Freire com a experiência de educação de jovens e adultos na década de 60 do século passado, também concebeu a educação como um mecanismo de emancipação dos trabalhadores analfabetos, com os quais desenvolveu um processo de alfabetização e conscientização. É possível que entre os objetivos e o alcance dessas ações exista uma longa distância. Mas é possível também ter ocorrido, a partir desta perspectiva de educação emancipatória, mudanças importantes no que diz respeito à formação crítica de milhares de trabalhadores. 
Adorno fala a partir do contexto da Alemanha nazista. Para dar conta do propósito educacional emancipador defendido, Adorno (1995) propôs que a educação deixasse de promover a competitividade entre as crianças. Afirmava que a competição é um princípio, no fundo, contrário a uma educação humana. Mas o mundo capitalista, dizia ele, vive e estimula a competição; nela vê um dos mecanismos da sobrevivência e do progresso. E a competição está inerente ao processo educacional contemporâneo.

Para Freire, que fala do contexto brasileiro - um país colonializado, comandado pelo poder do capitalismo, que promove diversos tipos de barbárie, de modo especial contra as parcelas mais pobres da sociedade, a educação é vista como o principal instrumento de resistência dos explorados e marginalizados. Entretanto, nas periferias e no campo, uma grande parcela da população ainda é privada de seus direitos básicos: saúde, educação, moradia digna etc.

Frente a essa realidade, Freire, então, propõe a educação como possibilidade emancipatória. Concebe a educação como um ato eminentemente político, que deve ser tomado como a prática da liberdade; nesta perspectiva idealizou um projeto de educação referenciado na realidade concreta da classe trabalhadora, com o propósito de colaborar, a partir da leitura crítica do mundo, para a leitura da palavra e para a formação da consciência, de modo a se tornar sujeito de suas ações e de sua história. Sobre o papel da educação dizia Freire (1996, p. 61), "ensinar exige compreender que a educação é uma forma de intervenção no mundo".

Em perspectiva semelhante, Pedro Casaldáliga, ao chegar à região do Araguaia, nordeste de Mato Grosso, em 1968,onde predominava o analfabetismo, ausência de políticas públicas de saúde, educação, trabalho e uma intensa concentração de terras, cujas consequências eram/são a exploração da classe trabalhadora e frequentes conflitos pela Reforma Agrária viu na educação um instrumento de luta e uma possibilidade de libertação da população pobre e marginalizada dos programas sociais.

\section{3 "Libertação" - no Araguaia: nasce uma Igreja, nasce uma Escola}

De início, não havia organizações representativas dos trabalhadores rurais na região. Em 1970 é constituída oficialmente a Prelazia de São Félix do Araguaia e o padre Pedro Casaldáliga é sagrado bispo em 1971. Na sua ordenação episcopal, Casaldáliga lança uma carta pastoral intitulada - Uma Igreja da Amazônia em Conflito com o Latifúndio e a Marginalização Social. Na carta, ele expressa a sua opção e compromisso com os pobres (posseiros/ 
trabalhadores rurais e os indígenas) e denuncia para as autoridades e para o mundo a violência instaurada contra a população da região, envolvendo a luta pela terra.

Observa-se por meio da Carta Pastoral e de outros documentos pesquisados, que, Pedro Casaldáliga tinha como atividade primordial a vida religiosa e o exercício sacerdotal, todavia, nota-se o funcionamento ideológico de princípios teológicos que reverberam outras práticas e outros modos de atuação da Igreja. O que justifica, por exemplo, a elaboração de uma cartadenúncia que marca, pelo discurso que a constitui, fissuras nas relações sempre - já estabelecidas entre a Igreja e os poderosos.

Uma igreja que se preocupava e atuava em questões sociais como a educação, empreendendo mecanismos de emancipação da classe trabalhadora. Irrompe aí, uma nova ordem na língua e na história. É o real da língua e da história. (GADET e PÊCHEUX, 2010).

De acordo com Casaldáliga (1991):

Com los años, y la nueva Teología em la Iglesia nueva, después del Vaticano II; com la experiencia cristiana de la lucha social; com la pobreza de ambiente y de espíritu que le han cincelado a uno en este Mato Grosso, también mi fe [...] se ha ido desnudando, más libre y verdadera. (CASALDÁLIGA, 1991, s. p.).

Ao ser estabelecida na região, a Prelazia de São Félix do Araguaia, dá início a um redirecionamento das ações da igreja, através de evidente, trabalho de formação política e confronto com as relações de feudalismo e escravidão, impostas pela grave problemática, produzida pela rápida e agressiva, expansão do latifúndio.

A união da igreja com a população local de retirantes, posseiros, índios e peões trabalhadores das fazendas é mediada pelo "Bispo Pedro" (como costumava ser chamado pela população local), as relações de força e de poder vão sendo alteradas e, a manutenção das famílias no campo passou a ser uma das suas principais bandeiras de sua atuação social.

Conforme assinalado por Valério e Ribeiro (2014):

As estratégias de enfrentamento com o latifúndio acabaram por se tornar a base pastoral da Prelazia que a cada conflito, ou ataque, solidificava ainda mais seu discurso de defesa dos oprimidos e confirmava a representação profética de si na figura de D. Pedro Casaldáliga. (VALÉRIO E RIBEIRO, 2014, p. 133).

De acordo com os autores, Dom Pedro Casaldáliga, agora Bispo emérito, passou a representar a aliança da igreja com os oprimidos. Nota-se, então, uma relação de contradição, se considerarmos o imaginário historicamente construído da relação entre povo e Igreja; entre Igreja e Estado; entre Estado e povo. 
Para Louis Althusser (1985), a Igreja está entre as instituições que fazem funcionar, em seu conjunto de práticas e rituais, o que ele define como mecanismo ideológico básico, isto é, a sujeição dos sujeitos sociais, e é isso que faz com que ela se constitua como Aparelho Ideológico de Estado (AIE).

Althusser nos fala que, assim como a Igreja, há uma série de outros AIE que funcionam sob a forma de instituições e que, de igual modo, propalam de forma mais ou menos sutil, mais ou menos explícita, uma ideologia. São eles:

\begin{abstract}
AIE religiosos (o sistema das diferentes Igrejas); AIE escolar (o sistema das diferentes “escolas" públicas e privadas); AIE familiar; AIE jurídico; AIE político (o sistema político, os diferentes Partidos); AIE sindical; AIE de informação (a imprensa, o rádio, a televisão, etc...); AIE cultural (Letras, Belas Artes, esportes, etc...). (Op. Cit, p. 68)
\end{abstract}

Quanto à "igreja do Araguaia", ao tecer uma preocupação com a educação, com a formação política e com a participação social das pessoas, produz um gesto que se traduz em resistência à sua condição primeira enquanto AIE, tal qual a definição de Althusser (1985).

Segundo Casaldáliga (1971), dada as condições de produção, foi preciso reformular todo o trabalho da pastoral:

Sentíamos o impasse da situação religioso-pastoral do nosso povo. Faltava tudo: em saúde, em ensino, em comunicações, em administração e em justiça. Faltava no povo a consciência dos próprios direitos humanos e coragem e a possibilidade de os reclamar. E o que não faltava era gritante, acusador. (CASALDÁLIGA, 1971, p. 25).

A fala de Casaldáliga acerca da opressão que a "falta de tudo" representava para o povo no Araguaia e da necessidade de consciência dos problemas vividos, como condição para resistir e alterar a realidade coloca no plano da evidência, a ausência de outros Aparelhos Ideológicos de Estado e abre a possibilidade para a leitura de um rompimento com sentidos cristalizados acerca da Igreja enquanto AIE: nesse caso, a Igreja em que ela própria é a agência de opressão e alienação das pessoas. Contudo, é possível perceber na fala de Casaldáliga que a Igreja no Araguaia se propunha a reelaborar suas ações.

Esse ressignificar da Igreja, reelaborado pela/na atuação da Prelazia de São Félix do Araguaia, é sustentado no modus operandi que é desencadeado na relação de defesa das causas do povo da região e de re-elaboração de mecanismos ideológicos que permitiram a ela a consciência e poder na disputa inevitável que havia nas relações de produção social.

De todo modo, é preciso observar que a Prelazia de São Félix do Araguaia não deixa de produzir um assujeitamento ideológico, haja vista que não deixa de ser Igreja, o que lhe confere condição para que também produza, pelas relações sociais que estabelece com o povo no 
Araguaia, um "atravessamento social" (ORLANDI, 2012). E, ainda que reelabore sua concepção de Igreja, de igual modo, produz efeitos de sentidos no processo de interpelação jurídica que regula e individualiza os sujeitos daquela região.

Dom Pedro Casaldáliga, um dos expoentes da Teologia da Libertação no Brasil, sustentou o desenvolvimento da práxis evangelizadora e política da igreja em meio à participação nos problemas sociais e conflitos instaurados no Araguaia daquela época, sendo o mais expressivo deles, o conflito agrário. Mudanças que ensaiaram seus primeiros passos motivados por ideais que ele mesmo ajudou a formular e que caracterizam, sobretudo, um trabalho sistemático de educação de base pela alfabetização de adultos, que, fundamentada, sobretudo, em Paulo Freire, deu início e sustentação a uma sólida estrutura para as organizações populares no campo, nos povoados e pequenas cidades.

\section{O Araguaia Faz Escola}

A partir de um movimento próprio de resistência, o povo começa a desenhar a luta em suas formas próprias de organização. Assim, aos poucos e, como o apoio que lhes era assegurado pela presença da Prelazia, a educação vai se configurando como possibilidade de maior integração e transformação da realidade social da população. Para Ferreira e Lopes (2004),

a violência, a exclusão social, a degradação ambiental, o descuido com as crianças, com os jovens, os índios, mulheres, negros, pobres e a desesperança do produtor familiar, celebram a fé na educação - importante vetor de construção da paz, da convivência solidária, da democracia e da justiça social. (FERRERIRA e LOPES, 2004, p. 170).

Ao considerar as condições de pobreza e de sujeição ao latifúndio, a Prelazia de São Félix do Araguaia viu na educação a possibilidade de romper com a ordem simbólica e social posta no Araguaia e, como afirmam Ferreira e Lopes, como condição para a construção da paz, da convivência solidária, da democracia e da justiça social.

Certamente, foi com essa fé na educação, como nos dizem os autores, que as ações educacionais desenvolvidas no Araguaia buscavam produzir efeitos de sentido capazes de desvelar a condição de opressão sob a qual viviam as pessoas e de sinalizar a necessidade de compreensão da vulnerabilidade social, cultural e econômica que essa opressão representava.

Logo, a fé na educação vai sendo constituída imbricada às representações e sentidos atribuídos ao fazer da Igreja. E a imagem de uma Igreja que (re)significava a voz e a força da 
população passava a fundir-se com a imagem que fora formulada para a educação, produzindo como efeito de sentido a permanência na terra e sobrevivência em meio às lutas.

Segundo Santos (2014):

Com a presença mais efetiva da igreja, chegaram pessoas com maior nível de formação, passando a oferecer maiores condições de instrução e de uma educação um pouco mais sistematizada. A partir daí as possibilidades aumentam e a educação vai ganhando novas formas e atingindo mais jovens (SANTOS, 2014, p.86).

Conforme o autor, a presença da igreja foi determinante para a institucionalização da educação na região e, como efeito já de um trabalho de formação, o povo passou a significar a educação como condição vital da luta e da resistência e, conforme assinalado no jornal Alvorada (22 de maio de 1970), “O povo esquecido, desesperançado, não pode mais esperar. Já bem dizia um sertanejo: 'a fome da cabeça é maior que a fome da barriga'." Metaforicamente, a educação é posta como o alimento capaz de manter a vida, de ampliar as condições de sobrevivência, de projeção de futuro.

Desde o início há, por parte da Prelazia, a compreensão de que a garantia de direitos ao povo da região necessariamente teria a formação das pessoas como um dos pontos determinantes para fortalecer a luta em prol da transformação da realidade social vivida.

Na Carta Pastoral, Uma Igreja da Amazônia em Conflito com o Latifúndio e a Marginalização Social, Casaldáliga (1971), fala da necessidade da educação escolar e da preocupação em construir uma educação que não fosse uma mera reprodução dos mecanismos ideológicos inerentes à escolarização, sobretudo, produzidos por parte da Igreja em outros tempos.

\begin{abstract}
Contra os nossos primeiros propósitos - fruto da velha experiência educacional da Igreja, fruto da própria experiência pessoal - decidimos enfrentar o problema do ensino: e construímos o ‘Ginásio Estadual do Araguaia’ de São Félix. Pago, em oitenta por cento (80\%) da importância, com donativos dos nossos amigos da Espanha, e sem nenhuma contribuição oficial da Prefeitura, do Estado ou do Governo Federal. Foi uma aventura quixotesca, necessária, porém. (CASALDÁLIGA, 1971, p. 26).
\end{abstract}

A criação do GEA, então, marcou o nascimento de uma escola de construção coletiva: "Que o Ginásio Estadual Araguaia, obra de todos nós, seja um dos esteios do nosso futuro". (Alvorada, 22 de maio de 1970). Entretanto, para ser coerente com a luta, um esteio do futuro, como afirma um dos moradores da região, teria de ser inventada e não reproduzida a partir dos preceitos ditados pelo Estado. 
E a invenção de uma escola necessária foi tecendo suas estruturas na arquitetura do povo, como é possível observar no relato de uma das professoras que atuou naquele período como agente pastoral da Prelazia:

\begin{abstract}
Seu José Rodrigues começou a mexer com as minhas inquietações: 'Minha filha, vamos lá pro Santo Antônio. Lá o bicho tá pegando, a fazenda cercou todo o patrimônio, colocou jagunços pra fazer medo no povo, tem gente querendo vender as terras e ir embora. Se não tiver uma boa escola pros meninos eles largam tudo e vão mesmo. A escola vai dar uma força, um motivo para ficar. Mas tem que ser boa'. (ALBUQUERQUE, 2007, p. 16)
\end{abstract}

Sendo assim, a população local produziu um novo imaginário de Escola, que pudesse significar a "escola boa" traduzida por Seu José Rodrigues. Uma escola que não possuía um modelo a ser seguido e que se caracterizasse na contramão do que foi produzido durante séculos inteiros por missionários religiosos filiados à formação discursiva romana.

Essa escola foi delineando seus contornos a cada dia nas práticas educativas do GEA: "Este ginásio é o início de uma nova alvorada. É o despertar de um longo sono. O GEA é o centro irradiador de uma nova luz, que se alastrará por este sertão afora, como fogo em palha". (Alvorada, 22 de maio de 1970). Uma escola que pretendeu desde o início sustentar-se na laicidade. Embora, em sua gênese, não tivesse a anulação do caráter doutrinário impresso pela religião cristã católica, preocupou-se constantemente com uma cuidadosa reelaboração e reinterpretação, com o propósito de promover "libertação".

\title{
5 “Libertação" é Educação
}

Balizada por referenciais teóricos de Paulo Freire ${ }^{1}$, a educação escolar na região passou a significar um exercício de luta e esperança, como tentativa de compreensão e superação da realidade vivida. E o fato de não possuir um modelo específico que pudesse produzir adaptações, determinou um processo contínuo de construção coletiva e de constante reelaboração a partir de si mesma. Sendo assim, constituiu-se por um entrecruzamento ideológico com a Escola Freireana, isto é, uma educação autêntica: "uma educação que liberte, que não adapte, domestique ou subjugue". (FREIRE, 1979, p. 22).

De acordo com Marluce Scaloppe (2012):

\footnotetext{
${ }^{1}$ Tendo em vista o recorte temporal de nossa pesquisa, acreditamos que provavelmente as obras de Freire que parametrizaram as ações educativas na região tenham sido: A Educação como Prática de Liberdade (1967); Conscientização - Teoria e Prática da Libertação: uma introdução ao pensamento de Paulo Freire (1979); Pedagogia do Oprimido (1987) e A Pedagogia da Esperança (1992). Porque essas foram as obras produzidas nesse período.
} 
Começavam a chegar a São Félix mais pessoas para atuar principalmente como professores. Primeiro, no Ginásio Estadual do Araguaia, construído pela Prelazia para implantar as primeiras séries do ensino fundamental, e depois em outras localidades. $\mathrm{O}$ método Paulo Freire foi adotado pela equipe e, junto com a alfabetização e evangelização, ia surgindo uma população mais consciente e politizada. (SCALOPPE, 2012, p. 70).

É possível perceber, por meio das contribuições da autora, que a prática de alfabetização, a partir das condições sócio-históricas, definida como "Método Paulo Freire", juntamente com as práticas de evangelização, corporificavam um projeto de formação social que pretendia produzir consciência crítica nas pessoas, como efeito de sentido do trabalho reflexivo entre escola/igreja.

Esse fundamento epistemológico se apresenta com mais clareza na medida em que levamos em consideração as relações estabelecidas num jogo circular entre marxismo, Teologia da Libertação, Igreja/Escola "libertadora" no Araguaia e os efeitos de sentido que essas relações podem produzir. "A educação é o grande meio de libertação do povo. Por isso o Ginásio Estadual do Araguaia veio abrir novos horizontes para São Félix do Araguaia e municípios circunvizinhos". (Jornal Alvorada - Inauguração do GEA, São Félix do Araguaia / Fonte: Arquivo da Prelazia de São Félix do Araguaia, 2012).

Casaldáliga afirma veementemente que a inspiração da Teologia da Libertação é o Evangelho de Cristo e o clamor dos pobres: "E é mentira afirmar que a Teologia da Libertação se inspira no marxismo: a Teologia da Libertação se inspira no Evangelho e na pobreza. Mas, evidentemente, utilizamos categorias marxistas e, graças a Marx, temos entendido melhor o capitalismo". (In: ESCRIBANO, 2014, p. 44).

Ao considerarmos que a matriz da Pedagogia do Oprimido é o materialismo histórico de Karl Marx, é possível traçar uma relação entre a alienação posta por Marx e a opressão descrita por Freire. O alienado de Marx é o oprimido de Freire. Logo, temos uma relação entre duas formações discursivas que se entrecruzam entre o oprimido/alienado e a condição da libertação/consciência.

Para Freire, o oprimido só vai superar essa condição na medida em que ela for desvelada, ou seja, se tomar consciência de tal opressão. Todavia, Marx afirma que: "Não é a consciência dos homens que determina o seu ser; ao contrário, é o seu ser social que determina a sua consciência”. (MARX, 2008, p. 47).

Em meio à experimentação exigida pelo processo de constante (re) construção é que se constituía a educação no Araguaia. Assim, foi se configurando de forma cada vez mais consistente a alfabetização de adultos, a inserção da educação escolar em comunidades 
indígenas e a preocupação constante com formação de professores. Um tripé que daria consistência a um princípio filosófico formativo que não se sustentaria em meras práticas de escolarização, mas na transformação das condições sociais.

A formação de adultos representaria condição para que as pessoas pudessem responder proativamente na luta, já que uma escola só para crianças e jovens como instrumento de defesa demandaria muito tempo para surtir seus efeitos. Conforme Albuquerque (2007):

Esperar pela contribuição dos 'meninos' seria tempo demais! Era preciso, certamente, de um núcleo de estudos com adultos. Eles embalariam o sonho tanto tempo sonhado de 'aprender as letras e as contas' e teriam espaço de discussão para pensar em conjunto e formular como deveria ser a escola do patrimônio. (ALBUQUERQUE, 2007, p. 23)

Sendo assim, a formação de adultos passou a ser um elemento de extrema relevância na luta por educação e nas outras tantas formas de resistência do povo no Araguaia. Desse modo, a alfabetização de adultos, tanto de indígenas quanto de não-índios, sustentada pelas concepções teórico- ideológicas de Freire, constituiu-se com a preocupação de que eles se tornassem pesquisadores, ou seja, que tivessem condições de reconhecer a agir sobre seus problemas.

A proposta de prover educação escolar nas comunidades indígenas se apresentou como o segundo pilar da educação na região. Seu princípio formativo não se limitava à mera preocupação com as práticas de escolarização, há tanto tempo empreendidas no funcionamento de aculturação ideológica desses povos, presentificadas na relação índio e branco. A perspectiva era justamente romper com esses sentidos e produzir novas formas de combate às práticas de violência que essas comunidades sofriam por representar, desde sempre, um empecilho para o projeto desenvolvimentista do governo.

Por fim, tem-se a formação de professor como possibilidade de sustentar e potencializar os avanços sonhados pelo povo. Isso nos parece ser uma espécie de legitimação do imaginário de escola elaborado pela população.

Pelo viés da formação, semelhante à perspectiva da Teoria Crítica, defendida por Adorno (1995), e “como prática de liberdade", como define Freire (1967, 1987,1992),os adultos deixam de ser analfabetos e passam a ser constituídos num jogo circular entre o que se aprende e o que se ensina, sendo ora aluno, ora professor, ainda que leigo - jargão recorrente na época.

O processo de formação dos professores, vinculado ao princípio filosófico elaborado nos primeiros passos da institucionalização da educação na região do Araguaia, traça um 
percurso que vai desde a alfabetização, habilitação em nível fundamental (naquela época definido como "primeiro grau”), habilitação em nível médio e superior.

A habilitação profissional de professores em nível fundamental foi uma ação única e inovadora no País, produto de uma articulação da Prelazia e promovido de forma integrada entre Secretaria de Estado de Educação (SEDUC-MT) e Secretarias Municipais da região.

A formação em nível médio contou com a parceria da Universidade Estadual de Campinas (UNICAMP) para a realização do curso, cujo nome: Inajá ${ }^{2}$,traduz fortemente os movimentos de resistência da região, sobretudo, os movimentos educacionais que ocorreram no Araguaia no final do século XX. Chegou a ser reconhecido pela UNESCO como um dos dez melhores trabalhos de Educação do Brasil e tornou-se "semente" de outros projetos educacionais, inclusive, para a formação em nível superior - Projeto de Licenciaturas Plenas Parceladas (ALBUQUERQUE e GATTI, 1997; ZATTAR, 2008).

\section{Educação na perspectiva da Glocalização}

Outro movimento social que reverbera o sentido de práticas coletivas dos sujeitos da região foi a institucionalização do Fórum de Educação do Araguaia (FEA), com representatividades da Prelazia de São Félix do Araguaia, Secretarias Municipais de Educação, e da UNEMAT.

O Fórum articulou a realização de cinco Mostras Regionais de Educação, coordenadas pela Secretaria Municipal de Educação de São Félix do Araguaia. Novos espaços de debate e discussões coletivas e novas formas de resistência no Araguaia puderam ser percebidos na ocasião dessas Mostras.

De acordo com Sousa (2014),

Como forma de dar início as discussões, em função de um grande projeto Regional de Educação, a secretaria de educação de São Félix juntamente com o Fórum realizou a I Mostra Regional de Educação do Araguaia, evento que chegou a sua $5^{\text {a }}$ versão, reunindo mais de 1500 pessoas da região e do Estado e inclusive os Ministros da Educação Cristóvam Buarque e Marina Silva, do Meio Ambiente. (SOUSA, 2014, p. 15).

Segundo a autora, o Fórum de Educação do Araguaia deu início a um projeto regional de educação e mais uma vez, como nas primeiras iniciativas dos movimentos sociais em favor

\footnotetext{
${ }^{2}$ Inajá é uma palmeira da região quando ela é derrubada e se faz a queimada, ela brota sem necessidade de se fazer nada. Ou seja, é uma palmeira que consegue morrer e voltar de novo a nascer, numa situação, num clima adverso, num lugar ruim, no meio do fogo, sem água, num tempo de seca... (CAMARGO, 1997: 17).
} 
da educação do Araguaia, é possível ver um envolvimento coletivo da região, fazendo circular sentidos de identidade coletiva atravessados por gestos de resistência.

Também Ferreira e Lopes (2004), definem as Mostras como espaço de compromisso coletivo dos municípios da região com a educação:

\begin{abstract}
A Mostra de Educação do Araguaia é o encontro que está na agenda da população da região. É um movimento que se afirma entre os educadores, administradores, políticos, pais, alunos e a prefeitura de São Félix do Araguaia, através da Secretaria Municipal de Educação, que orgulhosamente vem sediando, acolhendo e promovendo junto com os municípios que circunscrevem a região, a construção de focos de resistência e de esperança para o Brasil. (FERREIRA e LOPES, 2004, p. 170). (Grifos Nossos).
\end{abstract}

Ferreira e Lopes (op. cit.) definem as ações do coletivo de profissionais da educação dos municípios da região como um exercício de esperança e um gesto de resistência e dão destaque aos desafios que motivam a persistência dos sujeitos do Araguaia.

Na última Mostra, V Mostra Regional de Educação do Araguaia, Casaldáliga produziu um texto para a palestra que proferiu ao público de mais de 1500 pessoas.

Segundo ele, a natureza, a relevância e os efeitos de sentido produzidos na e a partir da educação no Araguaia são suficientes para imputar-lhe um caráter de "glocalização".

\begin{abstract}
Modestamente, mas também com satisfação histórica, podemos recordar que na nossa região, neste recanto que vai entre o Araguaia e o Xingu, do Pará ao travessão, por conta de certas administrações populares e com a ajuda da prelazia, a glocalização e a educação para a glocalização tem sido uma constante: Na aplicação do método Paulo Freire em plena ditadura militar ( o que nos custou a repressão conhecida); No famoso ginásio do Araguaia GEA; Na atividade constante de pesquisa, arquivo, publicações...Nas iniciativas culturais do Araguaia Pão e Circo, no teatro dos grupos de jovens, em atividades dos grupos de comadres, no estímulo a capoeira e outras manifestações de cultura popular; na própria opção pastoral da prelazia, como pastoral libertadora e em rede de comunidades. Na atividade indigenista, nas atividades da Associação de Educação e Assistência Social Nossa Senhora da Assunção-ANSA; Nas bem sucedidas experiências na formação de professores, em cursos ad hoc, como Inajá, Arara Azul, GerAção, Proformação, Parceladas e esta Mostra de Educação... $\mathrm{Na}$ constante abertura às lutas do Brasil e da América Latina em geral, sobretudo da querida Centro América; Na vivência da solidariedade, da intersetorialidade, melhor dizendo. Solidariedade que vem, solidariedade que vai. São Félix do Araguaia é uma humilde, mas real referência de Glocalização: Estamos entre o Araguaia e o Xingu, estamos na América Latina, estamos no mundo! (CASALDÁLIGA, 2004, palestra na V Mostra Regional de Educação do Araguaia).
\end{abstract}

De acordo com Casaldáliga, (op. cit), a educação no Araguaia, "uma real referência de Glocalização", se faz presente na América Latina e no mundo. 
Como se classifica, pois, essa educação? Que sentidos a palavra "glocalização" impõe às práticas de educação escolar produzidas no Araguaia?

Orlandi (2018) retoma contribuições de Carroué (2005) e define a mundialização como, "um processo geo-histórico de extensão progressiva do capitalismo em escala planetária e que é ao mesmo tempo, uma ideologia (o liberalismo), uma moeda (o dólar), um instrumento (o capitalismo), um sistema político (a democracia) e uma língua (o inglês)". (ORLANDI, 2018, p. 15).

A noção de mundialização apresentada pela autora (op. cit) nos permite questionar, se por um lado, a globalização produz um efeito de mundialização, que tanto pode representar "controle do econômico e do social" quanto resultar em "forte comando das relações, das divisões sociais" (idem), por outro lado, pode ela mesma abrir lacunas que permitam a reversão das relações de força e poder que exerce na ordem social que estabelece?

Como justifica a discursividade: com a ajuda da prelazia, a glocalização e a educação para a glocalização tem sido uma constante - produzida pelo líder da Prelazia que ficou conhecida no mundo inteiro por ter seu trabalho comparado a estratégias de guerrilha (no confronto com o avanço do latifúndio) e a liderança associada a subversivos e comunistas, justo por representar um empecilho ao modelo capitalista implantado na região - últimas décadas do século XX? O que essa contradição representa?

Sabe-se que globalização produz/tem produzido o abalo de estruturas sociais e institui novos padrões, ditados, sobretudo, pela atuação do capitalismo.

Para Hall (2006), a modernidade é o marco da nova ordem social instaurada pelo fenômeno da globalização. Já Aníbal Quijano (2005), afirma que, a globalização começou a se estabelecer ainda no período colonial instituído no século XVI, dada relação dos europeus com países americanos. Segundo o autor, a informação e a troca de produtos de consumo romperam limites geográficos e, como efeito, instauraram a "constituição da América e do capitalismo colonial/moderno e eurocentrado como um novo padrão de poder mundial”. (QUIJANO, 2005, p. 2). Enquanto Bauman (1999, p. 56), em uma perspectiva mais radical, define a globalização como a "nova desordem mundial".

Em se tratando do centro de nosso estudo, enquanto Adorno fala da educação como possibilidade de emancipação da classe trabalhadora, Freire, em outras palavras, fala da condição de ser libertadora de formas de opressão imposta pelo capitalismo. Já em Casaldáliga 
(2004), é possível produzir a interpretação da educação "glocal", que mistura sujeitos e identidades em prol de um objetivo comum, posta como uma linha tênue que avança nos limites do próprio capital para subvertê-lo, é mais do que emancipação e liberdade, é transgressão da própria ordem ideológica.

Sendo assim, tem-se no Araguaia, com base na definição de Casaldáliga, uma educação que permitiu a esses sujeitos participarem da lógica do capital, não apenas como mão de obra, a favor de indivíduos e da classe dominante, mas como protagonistas nos processos de produção social. E, dos muitos aspectos se pode observar, destaca-se:

A condição de transformar os sujeitos em proprietários e produtores de bens intelectuais - na atividade constante de pesquisa, arquivo, publicações... - e bens culturais, nas iniciativas culturais do Araguaia Pão e Circo, no teatro dos grupos de jovens, em atividades dos grupos de comadres, no estímulo a capoeira e outras manifestações de cultura popular; na própria opção pastoral da prelazia, como pastoral libertadora e em rede de comunidades.

O caráter extensionista: Na atividade indigenista, nas atividades da Associação de Educação e Assistência Social Nossa Senhora da Assunção-ANSA.

Os mecanismos de reprodução e manutenção ideológica: Nas bem-sucedidas experiências na formação de professores, em cursos ad hoc, como Inajá, Arara Azul, GerAção, Proformação, Parceladas e esta Mostra de Educação...

Por fim, podemos dizer que, enquanto Chaves e Ramos (2018, p. 68) definem a globalização a partir de um movimento que "emana do centro para as margens, tendo como um de seus efeitos o apagamento das especificidades de um povo", no Araguaia tem-se justamente o contrário.

As palavras de Casaldáliga (2004) textualizam um movimento inverso na relação do local com o global: "Estamos entre o Araguaia e o Xingu, estamos na América Latina, estamos no mundo!" e, que nos parece, produzir um efeito de fortalecimento, tanto da região, da população tida como menos favorecida e, um fortalecimento, sobretudo, da educação. Segundo ele, pela prática de uma educação constituída "na vivência da solidariedade, da intersetorialidade, melhor dizendo. Solidariedade que vem, solidariedade que vai".

\section{Considerações Finais}

Adorno, Freire e D. Pedro Casaldáliga, embora em contextos diferentes, veem na educação um grande potencial para a transformação das relações sociais e a garantia da emancipação da classe trabalhadora. 
Observa-se que Adorno, no contexto alemão, Freire no contexto brasileiro, Casaldáliga no contexto da Região do Araguaia, guardadas as devidas proporções, defendiam a transformação da ordem social e a emancipação da classe trabalhadora, tendo como principal instrumento a educação.

Em contraposição à educação reprodutora das desigualdades sociais, e com fins de colaborar com a transformação da sociedade e a emancipação da classe trabalhadora oprimida, Freire (1987) propôs a educação dialógica, a educação libertadora. Propôs pensar a escola como um mecanismo de transformação da ordem vigente, propôs a educação problematizadora e libertadora. Adorno propôs a educação para a emancipação, educação para evitar a barbárie e Casaldáliga propôs a Educação glocalizada para a libertação, por meio do Ginásio Estadual do Araguaia - GEA, do Método Paulo Freire e da Pastoral Libertadora. Contudo, produziram uma educação sustentada por formações ideológicas que colocavam em confronto escolarização versus formação, a educação no Araguaia foi se consolidando na identidade de cada comunidade e na necessidade de fortalecer a própria luta.

Foram muitas as ações que se traduziram no processo de construção da educação na região do Araguaia, materializando uma história coletiva. Se não fossem elas, todo o trabalho seria uma reprodução da própria opressão. Desse modo, as dificuldades, a resistência, a luta, foram significados por gestos e ações religiosas, políticas, literárias e educacionais que se materializaram por meio do teatro, das músicas, dos poemas, dos murais das igrejas, enfim, através do jeito de ser e de professar a fé e as práticas formativas das pessoas.

As diversas lutas lideradas por Casaldáliga, embora com novas configurações, atravessam mais de quatro décadas e desafiam as organizações populares e, sobretudo, a educação a se reinventar na defesa dos marginalizados, das classes populares, numa perspectiva local e global, ou seja, numa perspectiva glocal e libertadora como propôs Casaldáliga (2004).

Não há como mensurar as implicações das ações e ideias propagadas por Casaldáliga nos projetos de Educação na região do Araguaia, mas, é possível identificar, por meio de diversos estudos e pesquisas acadêmicas, marcas que evidenciam a sua atuação efetiva nas políticas de educação ali desenvolvidas.

Entendemos que o presente artigo coloca em evidência a estreita relação entre a atuação de Casaldáliga e os projetos de educação na região e se constitui em um instrumento de desvelamento e propagação das contribuições das ideias do religioso na construção de práticas pedagógicas de educação de perspectiva libertadora, postulada por Adorno, Freire e pelo próprio Casaldáliga. 
É importante considerar o histórico de influência que o mercado/capitalismo exerce sobre as políticas de educação no Brasil, bem como o regime político excludente e autoritário que se instala no país atualmente e se colocar na trincheira do resgate dos projetos coletivos e emancipatórios na região.

\section{Referências}

ADORNO, Theodor. Educação e Emancipação. Paz e Terra: São Paulo, 1995.

ALBUQUERQUE, J. G. Educação Escolar Indígena: do panóptico a um espaço possível de subjetivação na resistência. Tese (Doutorado em Linguística) Campinas, UNICAMP, 2007.

. e GATTI, D. A. Apresentação. In: CAMARGO, Dulce M. P. de. Projeto Inajá: uma experiência com professores leigos no Médio Araguaia. Campinas, SP: Editora Alínea, 1997.

ALTHUSSER, Louis. Aparelhos Ideológicos de Estado: nota sobre os aparelhos ideológicos de Estado. Tradução de Walter José Evangelista e Maria Laura Viveiros de Castro: Introdução Crítica de J. A. Guilhon Albuquerque. - Rio de Janeiro: Edições Graal, 1985.

ALVORADA, circular. Alvorada. São Félix do Araguaia, 22 de maio de 1970.

Alvorada. São Félix do Araguaia, 2012.

BAUMAN, Zygmunt. Globalização: as consequências humanas. Trad. Marcus Penchel. Rio de Janeiro: Ed. Zahar, 1999.

CALDART, Roseli S. Elementos para a construção de um projeto político e pedagógico da Educação do Campo. In: MOLINA, Mônica Castagna. JESUS, Sonia Meire Santos Azevedo de (org.). Contribuições para a construção de um projeto de Educação do Campo. Brasília, DF: Articulação Nacional "Por Uma Educação do Campo", n. 5, 2004.

CAMARGO, Dulce M. P. de. Projeto Inajá: uma experiência com professores leigos no Médio Araguaia. Campinas, SP: Editora Alínea, 1997.

CARROUÉ, L. La Mondialisation. Genèse, acteurs et enjeux. ÉditionsBréal, collection ESC, Paris, 2005.

CHAVES, A. S. e Ramos, L. "Ferramentas de Brancos": a tensão dos sentidos no discurso indígena sobre tecnologias digitais. In.: OLIVEIRA, R. R. R de. [et. al.] (orgs.). Linguagem e Significação: sujeitos indígenas. - Volume 1 - Campinas, SP: Pontes Editores, 2018.

CASAldÁligA, Pedro. Uma Igreja da Amazônia em Conflito com o Latifúndio e a Marginalização Social. Carta Pastoral. São Félix do Araguaia, 1971.

1991.

Llena de Dios, y tannuestra: antología mariana. Madrid: Publicaciones Claretianas, 
Glocalizar a Educação. Texto produzido na V Mostra Regional de Educação do Araguaia. São Félix do Araguaia-MT, 2004.

ESCRIBANO, Francesc. Descalço Sobre a Terra Vermelha: a vida do bispo Pedro Casaldáliga. Tradução: Carlos Moura. - 2. ed. - Campinas, SP: Editora da Unicamp, 2014.

FERREIRA. Eudson de Castro. e LOPES, Ana Maria de Oliveira. Tybysirá - Educação do Campo e Visibilidade Social: uma experiência no sertão do Araguaia. Brasília: Idéa Editora, 2004.

FREIRE, Paulo. Educação como Prática de Liberdade. Rio de Janeiro: Editora Paz e Terra Ltda, 1967.

Conscientização - Teoria e Prática da Libertação: uma introdução ao pensamento de Paulo Freire. São Paulo - SP: Cortez \& Moraes, 1979.

Pedagogia do Oprimido. 17ª ed. Rio de Janeiro: Paz e Terra, 1987.

Pedagogia da Esperança: um reencontro com a Pedagogia do Oprimido. Notas de Ana Maria Araújo Freire. Rio de Janeiro: Paz e Terra, 1992.

.Pedagogia da Autonomia: saberes necessários à prática educativa. $15^{\mathrm{a}}$ ed. São Paulo: Paz e Terra, 1996.

GADET, F. e PÊCHEUX, M. A Língua Inatingível. O Discurso na História da Linguística. Trad. MARIANI, B. e DE MELLO M. E. Chaves. Campinas: Editora RG, 2. ed, 2010.

HALL, Stuart. A Identidade Cultural na Pós-modernidade. Trad. Tomaz Tadeu da Silva e Guacira Lopes Louro. 11. ed. Rio de Janeiro: DP\&A, 2006.

MARX, Karl. Contribuição à Crítica da Economia Política. Tradução e Introdução de Florestan Fernandes. 2. ed. São Paulo: Editora Expressão Popular, 2008.

ORLANDI, Eni Pulcinelli. Discurso em Análise: sujeito, sentido e ideologia. 2. ed. Campinas, SP: Pontes Editores, 2012.

Conhecimento e Sociedade: da ciência, da escrita e da representação. In.: OLIVEIRA, R. R. R de. [et. al.] (orgs.). Linguagem e Significação: sujeitos indígenas. - Volume 1 Campinas, SP: Pontes Editores, 2018.

QUIJANO,Aníbal. Colonialidade do Poder, Eurocentrismo e América Latina. In.: LANDER, Edgardo (Org.). A Colonialidade do Saber: eurocentrismo e ciências sociais. Perspectivas latino-americanas. Buenos Aires: Argentina: Clacso, 2005, p. 227-278.

SCALOPPE, Marluce de Oliveira Machado. Práticas Midiáticas e Cidadania no Araguaia: o jornal Alvorada. Cuiabá: KCM Editora, 2012.

SANTOS, Paulo César M. Araguaia: entre palavras, roças e fuzis - a pedagogia dos agentes pastorais no nordestematogrossense, nos anos 1960/1970. Dissertação (Mestrado) - 
Universidade Federal de Mato Grosso, Instituto de Educação - Programa de Pós-Graduação em Educação. Cuiabá, 2014.

SOUSA, Maria de Lourdes Jorge. Tybysirá: Educação Pública Municipal de São Félix do Araguaia no Período de 1997-2004 - Gestão e Resultados: um estudo de caso. 2014. 31f. Trabalho de Conclusão do Curso de Especialização em Gestão Pública Municipal. Faculdade de Administração e Ciências Contábeis, Universidade Federal de Mato Grosso, São Félix do Araguaia-MT, 2014.

VALÉRIO, Mairon Escorsi.e RIBEIRO, Rosa Renilson. D. Pedro Casaldáliga e a Históriamemória do Araguaia (1970-1980). In: BRASETE, Maria Fernanda; MENDES, Olga Maria Castrillon e MAQUÊA, Vera (Orgs.). Literatura, Política, Religiosidades. Cáceres-MT: UNEMAT Editora, 2014.

ZATTAR, Neuza B. da S. Do IESC à UNEMAT: uma história plural 1978-2008. Cáceres-MT: Editora da UNEMAT, 2008. 